\title{
TINGKAT PENGETAHUAN DAN SIKAP REMAJA PUTERI TERHADAP BAHAYA ABORSI DI SMAN 1 MANADO
}

\author{
Mohammad Reza Husain \\ Joice J. Kaeng \\ Eddy Suparman \\ Fakultas Kedokteran Universitas Sam Ratulangi \\ Husain_reza92@yahoo.com
}

\begin{abstract}
Until now, abortion remains a controversial issue in Indonesian society, especially for adolescents. In Southeast Asia, the WHO estimates that 4.2 million abortions performed each year, of which 2,500 of which ended in death. Abortion rate in Indonesia is estimated at 2.3 million per year. Around 750,000 of them committed by juveniles. Of that number, 70,000 carried by unmarried girls. The lack of knowledge about reproduction and the dangers often age abortion known, can lead teens try to do things that have not been previously known. Where their activity is often a risk activity, such as sexual activity in aadolescentsrelationship that causing pregnant can lead to acts of abortion. Objective: To determine the knowledge and attitudes of young women toward abortion. Methods: This study was conducted at SMAN 1 Manado, the determination of the sample will use a concecutive sampling method to distribute questionnaires which contains several questions about abortion and how to react, each question will be rated. Results: There were 95 female students respondents of grader XII.Conclusion: 53 respondents (55.8\%) classified as having a good knowledge of the act of abortion. Also of attitude, 54 respondents (56.8\%) addressing abortionas well.
\end{abstract}

Keywords: abortion, teenage daughter.

\begin{abstract}
Abstrak: Sampai saat ini abortus masih merupakan masalah kontroversial di masyarakat Indonesia, terutama bagi para remaja. Diwilayah Asia Tenggara, WHO memperkirakan 4,2 juta abortus dilakukan setiap tahun, dimana 2.500 di antaranya berakhir dengan kematian. Angka abortus di Indonesia diperkirakan mencapai 2,3 juta pertahun. Sekitar 750.000 diantaranya dilakukan oleh remaja. Dari jumlah itu, 70.000 dilakukan oleh remaja putri yang belum menikah. Minimnya pengetahuan tentang reproduksi dan bahaya dari abortus yang diketahui remaja, dapat mengakibatkan remaja mencoba-coba untuk melakukan hal-hal yang belum diketahui sebelumnya. Dimana aktivitas mereka seringkali merupakan aktivitas yang beresiko, misalnya aktivitas seksual dalam berpacaran yang dilakukan remaja dapat menyebabkan terjadinya hamil sampai melakukan tindakan abortus. Tujuan: Untuk mengetahui pengetahuan dan sikap remaja putrid terhadap abortus. Metode: Penelitian ini dilakukan di SMAN 1 Manado, penentuan besar Sampel akan menggunakan cara Concecutive Sampling dengan membagikan kuesioner yang berisi beberapa pertanyaan seputar abortus dan cara menyikapinya yang setiap pertanyaannya diberi nilai. Hasil: Didapatkan responden sebanyak 95 siswi kelas XII. Kesimpulan: 53 responden (55.8\%) tergolong memiliki pengetahuan yang baik terhadap tindakan abortus. Begitu juga dari sikap, 54 responden (56,8\%) menyikapi tindakan aborsi itu dengan baik.
\end{abstract}

Kata kunci: Abortus, remaja puteri. 
Sampai saat ini abortus masih merupakan masalah kontroversial di masyarakat Indonesia. Namun terlepas dari kontroversi tersebut, abortus diindikasikan merupakan masalah masyarakat karena memberikan dampak pada kesakitan dan kematian ibu. Sebagaimana diketahui penyebab utama kematian ibu hamil dan melahirkan adalah perdarahan, infeksi dan eklamsia. Namun sebenarnya abortus juga merupakan salah satu penyebab kematian ibu, hanya saja muncul dalam bentuk komplikasi perdarahan dan sepsis, hal ini merupakan indikasi bahwa hingga saat ini abortus masih merupakan masalah kontroversi di masyarakat. ${ }^{1}$

Pada remaja perempuan yang hamil, kendala terbesar adalah rasa takut dan tidak tahu harus mencari konseling. Hal ini menyebabkan penundaan remaja mencari pertolongan pelayanan aman, dan sering kali terperangkap di praktek abortus yang tidak aman. Dari 46 juta abortus per tahun, 20 juta dilakukan dengan tidak aman, 800 wanita diantaranya meninggal karena komplikasi abortus tidak aman. ${ }^{2}$

Data BKKBN menunjukkan, Survei Kesehatan Reproduksi Remaja Indonesia 2002-2003 menyebutkan, remaja yang mengaku memiliki teman yang pernah berhubungan seksual sebelum menikah pada usia 14-19 tahun mencapai 34,7 persen untuk perempuan dan 30,9 persen untuk laki-laki. Mereka yang berumur 20-24 tahun yang pernah melakukan hal serupa ada 48,6 persen untuk perempuan dan 46,5 persen untuk laki-laki. $^{3}$ Hal serupa didapat dari data Komisi Nasional Perlindungan Anak tahun 2008. Dari 4.726 responden siswa SMP dan SMA di 17 kota besar diperoleh hasil, 97 persen remaja pernah menonton film porno serta 93,7 persen pernah melakukan ciuman, meraba kemaluan, ataupun melakukan seks oral. Sebanyak 62,7 persen remaja SMP tidak perawan dan 21,2 persen remaja mengaku pernah aborsi. $^{4}$ Menurut Survey Demografi Kesehatan Indonesia (SKDI) 2004 tentang aborsi atau pengguguran kandungan, tingkat aborsi di Indonesia sekitar 2 sampai 2,6 juta kasus pertahun, yang 30\% dari aborsi tersebut dilakukan oleh mereka di usia 15-24 tahun. ${ }^{5}$

$$
\text { World Health Organization }
$$
(WHO) memperkirakan ada 22 juta kejadian aborsi tidak aman (unsafe abortion) di dunia, ${ }^{6}$ 9,5 \% (19 dari 20 juta tindakan aborsi tidak aman) diantaranya terjadi di negara berkembang. Sekitar 13 $\%$ dari total perempuan yang melakukan aborsi tidak aman berakhir dengan kematian. Diwilayah Asia Tenggara, WHO memperkirakan 4,2 juta aborsi dilakukan setiap tahun, dan sekitar 750.000 sampai 1,5 juta terjadi di Indonesia, dimana 2.500 di antaranya berakhir dengan kematian. Angka aborsi di Indonesia diperkirakan mencapai 2,3 juta pertahun. Sekitar 750.000 diantaranya dilakukan oleh remaja. ${ }^{7}$ Dari data yang didapatkan, menyatakan bahwa jumlah aborsi di Indonesia dilakukan oleh 2 juta orang tiap tahun, dari jumlah itu, 70.000 dilakukan oleh remaja putri yang belum menikah.

Masalah aborsi pada remaja perlu mendapatkan penanganan serius, karena masalah tersebut paling banyak muncul di negara-negara berkembang seperti Indonesia karena kurang tersedianya akses untuk mendapat informasi mengenai aborsi. Hal itu terbukti dari banyak penelitian menyatakan tingginya angka aborsi yang tidak aman sehingga menyebabkan kematian oleh karena kurangnya pengetahuan remaja putri terhadap bahaya aborsi. ${ }^{8}$

Berdasarkan latar belakang masalah di atas maka penulis tertarik untuk meneliti tentang tingkat pengetahuan dan sikap remaja putri terhadap bahaya aborsi dan penelitian 
akan dilakukan di SMA Negeri 1 Manado.

\section{METODE}

Penelitian ini termasuk pada jenis penelitian deskritif dengan pendekatan cross sectional. Dilakukan pada bulan bulan November 2012 sampai dengan Januari 2013 di di SMA Negeri 1 Manado. Populasi dalam penelitian ini adalah seluruh siswa wanita dari kelas $\mathrm{X}$ sampai kelas XII SMA Negeri 1 yang berjumlah 1253 orang. Penentuan besar Sampel akan diambil dengan cara Concecutive Sampling yang berjumlah 92 orang.

\section{HASIL}

Penelitian ini dilakukan pada siswi SMA Negeri 1 Kota Manado pada bulan Desember 2012. Besar sampel yang didapatkan sebanyak 95 subjek.

Data Karakteristik

Tabel 1. Sebaran Responden berdasarkan umur

\begin{tabular}{ccc}
\hline Umur & Jumlah & Persentase (\%) \\
\hline 14 & 5 & 5.4 \\
15 & 17 & 17.9 \\
16 & 34 & 35.8 \\
17 & 29 & 30.5 \\
18 & 7 & 7.4 \\
\hline Total & 92 & 100.0 \\
\hline
\end{tabular}

Tabel 2. Sebaran Responden berdasarkan tingkat kelas

\begin{tabular}{ccc}
\hline $\begin{array}{c}\text { Tingkat } \\
\text { kelas }\end{array}$ & Jumlah & $\begin{array}{c}\text { Persentase } \\
(\%)\end{array}$ \\
\hline X & 14 & 14.7 \\
XI & 25 & 26.3 \\
XII & 56 & 58.9 \\
\hline Total & 95 & 100.0 \\
\hline
\end{tabular}

Tabel 3. Sebaran Responden Berdasarkan Sumber Informasi tentang Aborsi

\begin{tabular}{|c|c|c|c|}
\hline \multicolumn{4}{|l|}{$\begin{array}{l}\text { Sumber } \\
\text { Informasi }\end{array}$} \\
\hline & Jawaban & Jumlah & $\begin{array}{l}\text { Persentase } \\
\text { (\%) }\end{array}$ \\
\hline \multirow[t]{2}{*}{ Koran } & $\mathrm{Ya}$ & 63 & 66.3 \\
\hline & Tidak & 32 & 33.7 \\
\hline Total & & 95 & 100.0 \\
\hline \multirow[t]{2}{*}{ Majalah } & $\mathrm{Ya}$ & 31 & 32.6 \\
\hline & Tidak & 64 & 67.4 \\
\hline Total & & 95 & 100.0 \\
\hline \multirow[t]{2}{*}{ Buku } & $\mathrm{Ya}$ & 35 & 36.8 \\
\hline & Tidak & 60 & 63.2 \\
\hline Total & & 95 & 100.0 \\
\hline \multirow[t]{2}{*}{ Televisi } & Ya & 80 & 84.2 \\
\hline & Tidak & 15 & 15.8 \\
\hline Total & & 95 & 100.0 \\
\hline \multirow[t]{2}{*}{ Radio } & $\mathrm{Ya}$ & 15 & 15.8 \\
\hline & Tidak & 80 & 84.2 \\
\hline Total & & 95 & 100.0 \\
\hline \multirow[t]{2}{*}{ Internet } & $\mathrm{Ya}$ & 57 & 60.0 \\
\hline & Tidak & 38 & 40.0 \\
\hline Total & & 95 & 100.0 \\
\hline Teman & $\mathrm{Ya}$ & 48 & 50.5 \\
\hline sebaya & Tidak & 47 & 49.5 \\
\hline Total & & 95 & 100.0 \\
\hline Guru & $\mathrm{Ya}$ & 33 & 34.7 \\
\hline kelas & Tidak & 62 & 65.3 \\
\hline Total & & 95 & 100.0 \\
\hline
\end{tabular}

Tabel 4. Sebaran Responden Berdasarkan tingkat pengetahuan terhadap Abortuspada bulan Desember 2012 di SMA N 1 Manado

\begin{tabular}{cccc}
\hline Variabel & $\begin{array}{c}\text { Katego } \\
\text { ri }\end{array}$ & $\begin{array}{c}\text { Jumla } \\
\text { h }\end{array}$ & $\begin{array}{c}\text { Persentas } \\
\text { e (\%) }\end{array}$ \\
\hline Pengetahu & Baik & 53 & 55.8 \\
an & Sedang & 37 & 38.9 \\
& Kurang & 5 & 5.3 \\
\hline Total & & 95 & 100.0 \\
\hline
\end{tabular}


Tabel 5. Sebaran Responden berdasarkan sikap terhadap Aborsipada bulan Desember 2012 di SMA N 1 Manado

\begin{tabular}{cccc}
\hline Variabel & Kategori & Jumlah & $\begin{array}{c}\text { Persentase } \\
(\%)\end{array}$ \\
\hline Sikap & Baik & 54 & 56.8 \\
& Sedang & 36 & 37.9 \\
& Kurang & 5 & 5.3 \\
\hline Total & & 95 & 100.0 \\
\hline
\end{tabular}

\section{PEMBAHASAN}

Berdasarkan karakteristik umur responden dalam penelitian ini, keseluruhan responden masuk pada kriteria usia remaja dengan rentan usia 14-20 tahun. Sebagian besar responden yaitu sebanyak 34 responden (35.8\%) berumur 16 tahun, 29 responden (30.5\%) berumur 17 tahun, 17 responden $(17,9 \%)$ berumur 15 tahun, 7 responden $(7,4 \%)$ berumur 18 tahun dan 5 responden (5,3\%) berumur 14 tahun. Hasil penelitian ini sejalan dengan hasil penelitian Fadilah Arbi Dyah Kusumastuti yang sebagian besar didominasi oleh responden berusia 16 tahun $(74,45 \%)$ dan responden yang berusia 15 tahun $(24,46 \%)$ dan hasil penelitian Tinceuli Sinaga yang sebagian besar responden berusia 16 tahun (37,97\%). Rentan Usia 14 - 16 tahun merupakan usia remaja pertengahan. Smith dan Anderson menyatakan bahwa munculnya dorongan seksual terjadi pada remaja pertengahan yaitu usia 14 sampai 16 tahun. Menurut Soetjiningsi ciri khas remaja pertengahan yaitu para remaja sudah mengalami pematangan fisik secara penuh (anak perempuan sudah mengalami haid). ${ }^{9,12}$

Berdasarkan karakteristik tingkat pendidikan, diketahui sebanyak 56 responden (58.9\%) duduk di kelas XII, 25 responden (26.3\%) duduk di kelas XI dan 14 responden (14.7\%) duduk di kelas $\mathrm{X}$. Semakin tinggi tingkat pendidikan seseorang, diharapkan akan meningkatkan kemampuan mengembangkan potensi diri, perubahan sikap dan tata laku sehingga meningkatkan kedewasaan. Dalam hal ini tingkat pendidikan menjadi factor yang berpengaruh pada tingkat pengetahuan, sikap dan tindakan seseorang dalam menjalani kehidupan bersosial. ${ }^{10}$

Berdasarkan sumber informasi tentang bahaya aborsi diketahui sumber informasi yang terbanyak didapatkan dari televisi yang dinyatakan oleh 80 responden (84.2\%), 63 responden (66.3\%) dari Koran, 57 responden (60\%) dari internet, 48 responden (50.5\%) dari guru, 31 responden (32.6\%) dari majalah, dan 15 responden (15.8\%) dari radio. Hal ini sejalan dengan hasil penelitian Yan Ardiansyah yang menunjukkan sumber informasi responden tentang abrosi terbanyak didapatkan melalui televisi yaitu 83 responden dengan persentase (78,3\%).

Pemberian pendidikan masyarakat mengenai isu aborsi akan menghasilkan dukungan masyarakat, yang sangat diperlukan untuk mengimplementasikan pelayanan kesehatan reproduksi masyarakat khususnya remaja. Dengan pendidikan masyarakat juga akan meningkatkan pengetahuan masyarakat mengenai resiko aborsi dan pencegahan aborsi serta memberikan kontribusi pada penurunan angka KTD (kehamilan tidak diinginkan) dan juga permintaan aborsi. Meningkatkan pengetahuan mengenai aborsi dapat dilakukan melalui kampanye menggunakan media massa seperti televisi, Koran, majalah, radio, dan oleh karena kecanggihan teknologi seperti komputer yang sebagian besar remaja dapat mengoperasikannya, internet dapat juga digunakan sebagai media informasi untuk meningkatkan pengetahuan mengenai aborsi. ${ }^{11}$

$$
\text { Pada tabel } 4.4 \text { diatas }
$$
memperlihatkan tingkat pengetahuan 
responden tentang abortus terbanyak yaitu 53 responden (55.8\%) memiliki tingkat pengetahuan yang baik, 37 responden (38.9\%) memiliki tingkat pengetahuan sedang, dan 5 responden (5.3\%) memiliki tingkat pengetahuan kurang tentang bahaya aborsi. Dari tabel dapat dilihat bahwa tingkat pengetahuan terbanyak responden tetang bahaya aborsi adalah baik. Hal ini dapat dikarenakan responden memiliki akses yang mudah dalam memperoleh informasi tersebut baik dalam media cetak, televisi, atau internet. Sedangkan untuk responden yang memiliki tingkat pengetahuan sedang tentang bahaya aborsi bisa dikarenakan responden kurang aktif dalam mencari informasi baik dalam media cetak, televisi, atau internet mengenai bahaya aborsi. ${ }^{13}$

Salah satu faktor yang mempengaruhi pengetahuan responden tentang bahaya aborsi salah satunya adalah pendidikan, informasi dan pengalaman. Menurut Notoadmojo, ada beberapa factor yang mempengaruhi pengetahuan seseorang, pendidikan adalah upaya untuk memberikan pengetahuan sehingga terjadi perubahan. Informasi adalah orang yang memiliki sumber informasi yang lebih banyak akan memiliki pengetahuan yang lebih luas pula. Sumber informasi dari pengajar maupun media, sikap kepercayaan, budaya masyarakat sangat siswi guna memperluas ilmu pengetahuan. Pengalaman pribadi serta perilaku seseorang akan menjadi sumber pengetahuan, begitu pula dengan tingkat kemampuan seseorang akan menambah pengetahuan informasi. ${ }^{13}$

$$
\text { Dan dari tabel } 4.5
$$

memperlihatkan sikap responden terhadap bahaya aborsi. Diketahui sebanyak 54 responden (56.8\%) memiliki sikap yang baik, 36 responden $(37,9 \%)$ memiliki sikap yang sedang dan 5 responden (5.3\%) memiliki sikap yang kurang terhadap aborsi. Sikap adalah respon tertutup seseorang terhadap stimulus atau objek tertentu, yang sudah melibatkan faktor pendapat dan emosi yang bersankutan. Dari tabel dapat dilihat bahwa sikap responden tetang bahaya aborsi terbanyak adalah baik. Hal ini sejalan dengan hasil penelitian Tinceuli Sinaga yang seluruh responden memiliki sikap yang baik tentang bahaya aborsi bagi kesehatan alat reproduksi wanita. Hal ini dapat dikarenakan oleh tingkat pengetahuan yang baik dari responden akan dampak buruk dari aborsi terlebih bila aborsi yang dilakukan dengan cara tidak aman seperti aborsi dengan tindakan sendiri, bantuan dukun, dengan akupuntur ataupun melalui bantuan orang pintar. Tingkat pengetahuan yang siswi baik akan mempengaruhi cara siswa bersikap, sehingga siswa dalam hal ini dapat menentukan tindakan yang baik dalam menghadapi masalah kehidupan. Hal ini sesuai dengan pernyataan Notoadmojo yang menyatakan sikap, seseorang dapat berubah dengan diperolehnya tambahan informasi tentang objek tertentu, melalui persuasif serta tekanan dari kelompok sosialnya., 11, 12

\section{SIMPULAN}

1. Kesimpulan yang diambil berdasarkan beberapa pertanyaan pada tabel 4.4 yang sudah diberikan kepada responden, setelah diteliti data tersebut didapatkan bahwa rata-rata siswi SMAN 1 Manado memiliki pengetahuan yang baik terhadap bahaya tindakan aborsi.

2. Kesimpulan yang dapat diambil berdasarkan beberapa pernyataan pada tabel 4.5 yang sudah diberikan kepada responden, setelah diteliti data tersebut didapatkan bahwa siswi SMAN 1 Manado menyikapi dengan benar terhadap bahaya tindakan aborsi. 


\section{SARAN}

1. Bagi Sekolah

Diharapkan agar pihak sekolah untuk memberikan penyuluhan dan melakukan seminar kepada siswa dan siswi perihal dampak buruk dari sex bebas yang berujung pada tindakan aborsi.

2. Bagi Siswa dan Siswi

Diharapkan agar siswa dan siswi agar dapat aktif dalam memperoleh informasi dan saling membagi informasi tentang bahaya aborsi tidak aman terhadap organ reproduksi dan segala dampak negatif yang ditimbulkan akibat aborsi tidak aman.

3. Bagi Peneliti Lain

Pada penelitian selanjutnya diharapkan agar dapat mencari hubungan atau korelasi ataupun faktor-faktor yang mempengaruhi terjadinya aborsi pada remaja putri.

\section{DAFTAR PUSTAKA}

1. Dila N. Aborsi. [homepage on the Internet]. 2012 [cited 23 Oktober 2012]. Availablefrom

:http://www.academia.edu/4869457.pdf.

2. Penyebab-penyebab Abortus Spontan. [homepage on the Internet]. 2012 [cited 9 November 2012]. Available from: http://repository.usu.ac.id/bitstream/1234 56789/23479/5.pdf

3. Muliyati. Faktor-faktor yang berhubungan dengan perilaku gaya pacaran pada pada siswa SMU X dan MAN Y Kabupaten Sidrap propinsi Sulawesi Selatan. Depok: FKMUI; 2012

4. Imanda KP. Faktor-faktor yang berhubungan dengan perilaku pemberian pendidikan seks untuk anak oleh orang tua siswa Madrasah Ibtidaiyah Hayatul Islamiyah. Depok: FKMUI; 2012
5. Pengaruh Paparan Media Internet dan Teman Sebaya Terhadap Perilaku Seks Bebas Pada Remaja Kelas 2 SMA XYZ Tahun 2012. [homepage on the Internet]. 2012 [cited 13 November 2012]. Available from: http://repository.usu.ac.id/bitstream/1234 56789/34144/5/.pdf.

6. Sneeringer KR. Billings DL. Roles of pharmacists in expanding access to safe and effective medical abortion in developing countries. Journal of public health policy Vol. 33, 2, 218-229

7. Malanda N. Konsep diri remaja yang melakukan aborsi. Depok: FPUG; 2012

8. Nurhidayah DC. Hubungan tingkat pendidikan dengan respon terhadap kehilangan pada pasien abortus. Purwokerto: FKIK; 2008

9. Kusumastuti Fadhilla A. D.Hubungan Antara Pengetahuan Dengan Sikap Seksual Pranikah Remaja. Program Studi D IV Kebidanan Fakultas Kedokteran Universitas Sebelas Maret, Surakarta. 2010. Available from: http:// eprints.uns.ac.id/126/1/16709030920101 0411.pdf (Diakses 2 januari 2014)

10. Andrian dan Kuntoro. Abortus Spontan Pada Pernikahan Usia Dini. Jurnal Biostatistika dan Kependudukan Vol. 2, No. 1 Juli 2013: 1-9. Available from: http://210.57.222.46/index.php/JBK/artic le/viewFile/1045/1032.pdf (Diakses tanggal 3 januari 2014)

11. Suryoputro A. Faktor-faktor yang mempengaruhi perilaku seksual remaja di jawa tengah: implikasinya terhadap kebijakan dan layanan kesehatan seksual dan reproduksi. UNDIP: Semarang; 2006

12. Sinaga Tinceuli. Pengetahuan dan Sikap Remaja Putri Terhadap Aborsi Dari Kehamilan Tidak Dikehendaki Di Sekolah Menengah Umum Negeri I Pematang Siantar Kecamatan Siantar Kabupaten Simangulun Tahun 2007. Fakultas Kesehatan Masyarakat Universitas Sumatera Utara. 2007. 
Available

from:

http://repository.usu.ac.id/bitstream/1/08

E01570.pdf (Diakses tanggal 3 januari 2014)

13. Untari Lilis P. Tingkat Pengetahuan Remaja Putri Tentang Bahaya Aborsi Di Kelas XI SMK Muhammadiyah Sragen
Tahun 2013. Program Studi Diploma III

Kebidanan Sekolah Tinggi Ilmu

Kesehatan Kusuma Husada, Surakarta.

2013. Available from:

http://digilib.stikeskusumahusada.ac.id/fi les/disk1/9/01-gdl-lilispraun-429-1-

lilispr-0.pdf. (Diakses tanggal 3 januari 2014) 